\title{
Article \\ Outcome of Elderly Patients with Venous Thromboembolism Treated with Direct Oral Anticoagulants-A Retrospective Cohort Study
}

\author{
Irit Ayalon-Dangur ${ }^{1,+}{ }^{+}$, Yakov Vega ${ }^{2,+}$, Miriam Rozi Israel ${ }^{1}$, Alon Grossman ${ }^{2,3}$, Galia Spectre ${ }^{2,4}$, Tzippy Shochat ${ }^{5}$, \\ Leonard Leibovici ${ }^{1,6}$ and Anat Gafter-Gvili ${ }^{2,4,6, *}$ \\ 1 Internal Medicine E, Rabin Medical Center, Beilinson Campus, Petah Tikva 49100, Israel; \\ iritayalon1234@gmail.com (I.A.-D.); Miroz187@gmail.com (M.R.I.); Leibovici@clalit.org.il (L.L.) \\ 2 Sackler Faculty of Medicine, Tel Aviv University, Tel Aviv 69978, Israel; yakovega@gmail.com (Y.V.); \\ ALONG@clalit.org.il (A.G.); galiasp1@clalit.org.il (G.S.) \\ 3 Internal Medicine B, Rabin Medical Center, Beilinson Campus, Petah Tikva 49100, Israel \\ 4 Institute of Hematology, Davidoff Cancer Center, Rabin Medical Center, Beilinson Campus, \\ Petah Tikva 49100, Israel \\ 5 Bio-Statistical Unit, Rabin Medical Center, Beilinson Campus, Petah Tikva 49100, Israel; tzippysh@clalit.org.il \\ 6 Internal Medicine A, Rabin Medical Center, Beilinson Campus, Petah Tikva 49100, Israel \\ * Correspondence: gaftera@gmail.com \\ + Both authors contributed equally to this work.
}

\section{check for} updates

Citation: Ayalon-Dangur, I.; Vega, Y.; Israel, M.R.; Grossman, A.; Spectre,

G.; Shochat, T.; Leibovici, L.; Gafter-Gvili, A. Outcome of Elderly

Patients with Venous

Thromboembolism Treated with Direct Oral Anticoagulants-A Retrospective Cohort Study. J. Clin. Med. 2021, 10, 5673. https:// doi.org/10.3390/jcm10235673

Academic Editor: Karsten Keller

Received: 13 October 2021

Accepted: 27 November 2021

Published: 1 December 2021

Publisher's Note: MDPI stays neutral with regard to jurisdictional claims in published maps and institutional affiliations.

Copyright: (c) 2021 by the authors. Licensee MDPI, Basel, Switzerland. This article is an open access article distributed under the terms and conditions of the Creative Commons Attribution (CC BY) license (https:// creativecommons.org/licenses/by/ $4.0 /)$.
Abstract: Introduction: Randomized controlled trials that compared direct oral anticoagulants (DOACs) to vitamin K antagonists (VKA) for the treatment of venous thromboembolism (VTE), demonstrated both efficacy and safety of DOACs. The aim of the current study was to compare DOACs to VKA for the treatment of VTE in the elderly, in a real-life setting. Methods: A retrospective cohort study was performed in Rabin Medical Center encompassing a 7-year period. Hospitalized patients $>65$ years, with a diagnosis of VTE discharged with DOACs or VKA were included. The primary outcome was a composite of all-cause mortality, major bleeding, recurrent VTEs and hospitalizations throughout the follow-up period of one year. Results: A total of 603 patients were included in the final analysis. The mean age was $79.6 \pm 8.5$ years. The primary composite outcome occurred in $74.6 \%$ and $56.7 \%$ of the patients in the VKA group and DOACs group, respectively, hazard ratio $0.59,95 \%$ confidence interval 0.46 to 0.76 , in favor of the DOACs group. In a matched cohort analysis, the results were the same as the original analysis. Conclusion: In the elderly population, treatment of VTE with DOACs was associated with a lower rate of the composite outcome. DOACs are safe and effective for elderly patients with VTE.

Keywords: elderly; venous thromboembolism; deep vein thrombosis; pulmonary embolism; direct oral anticoagulants; vitamin K antagonists; enoxaparin

\section{Introduction}

Venous thromboembolism (VTE) is the third most common cause of morbidity and mortality from cardiovascular disease after myocardial infarction (MI) and stroke. The annual incidence of VTE is estimated to be around 1.5-3.0/1000 cases [1,2]. The conventional therapy until recently was parenteral treatment with low molecular weight heparin (LMWH) for at least five days and vitamin K antagonists (VKA) as warfarin during this time period and continued for a minimum of three months [3]. Large randomized controlled trials that compared direct oral anticoagulants (DOACs) to VKA for the treatment of VTE-including AMPLIFY, which assessed apixaban; RE-MEDY, which assessed dabigatran; EINSTEIN, which assessed rivaroxaban; and Hokusa-VTE, which assessed edoxaban-demonstrated both efficacy (non-inferiority regarding the primary efficacy outcome of recurrent VTE or VTE related death) and safety of DOACs [1,4-8]. Based on 
these trials, the American College of Chest Physicians (ACCP, CHEST) 2016 guidelines recommend the use of any of the DOACs over VKA treatment (grade 2B recommendation) [9]. The European Society of Cardiology (ESC) guidelines for the diagnosis and management of acute pulmonary embolism recommend that when oral anticoagulation is initiated in a patient with PE who is eligible for a DOACs, a DOACs is the recommended form of anticoagulant (grade 1 recommendation) [10]. The American Society of Hematology (ASH) 2020 guidelines for management of venous thromboembolism suggest using direct oral anticoagulants over vitamin $\mathrm{K}$ antagonists as well [11].

VTEs are more prevalent in the elderly. The risk for VTE is four to six times greater in patients above the age of 70 years than the risk in patients younger than 70 [12], and the risk for VTE is doubled with each decade [13]. In addition to the higher prevalence of VTEs in the elderly, the bleeding risk is increased as well. The risk of major bleeding in patients using anticoagulants is $2.5 \%$ per year in patients older than 80 years compared to $0.9 \%$ per year in patients younger than $80[14,15]$.

In the three large trials quoted above $[1,4,5]$ the mean age examined was 55 years (SD 15). Patients older than 70 years were included, yet the percentage of elderly patients over the age of 75 was negligible (in the AMPLIFY, RE-COVER and EINSTEIN trials, $14 \%, 10.4 \%$ and $18 \%$, respectively, representing about 2500 patients in total). A systematic review and meta-analysis which extracted data from the AMPLIFY, RE-MEDY, EINSTEIN and Hokusai trials found that DOACs showed the same or greater efficacy compared with vitamin $\mathrm{K}$ antagonists in elderly patients older than 75 years old [16]. Another large systematic review, based on the same studies found that treatment with DOACs is as effective as warfarin and a safer alternative in an elderly population [17].

Nevertheless, no RCTs were conducted specifically in the elderly population. Patients included in RCTs do not necessarily represent patients seen in daily clinical practice.

The aim of the current study is to compare DOACs to LMWH/VKA in terms of efficacy and safety, for the treatment of VTE in the elderly, in the real-life setting.

\section{Materials and Methods}

\subsection{Study Design}

A retrospective cohort study was performed in Rabin Medical Center encompassing a 7-year period from January 2012 to December 2018. The study was approved by the Rabin Medical Center (RMC) institutional review board (confirmation number 0165-18-RMC). The trial was conducted in accordance with the principles of the Declaration of Helsinki. Our study is retrospective and therefore informed consent was waived by the institutional review board.

\subsection{Study Population}

All patients $>65$ years old, who were hospitalized with either a symptomatic, confirmed diagnosis of new lower extremity deep vein thrombosis (DVT) and/or pulmonary emboli (PE) and who were either discharged with DOACs (rivaroxaban, apixaban or dabigatran) or LMWH/VKA were included in the analysis. Patients who developed DVT or PE during the hospitalization were excluded. Patients with a contraindication to anticoagulation (i.e., active bleeding, platelet count $<50,000 / \mathrm{microL}$, major trauma, history of intracranial hemorrhage (ICH)) were excluded. The diagnosis of either DVT or PE was confirmed by imaging studies of lower extremity (Doppler ultrasound for DVT) and CT angiography or perfusion scan for PE. The final cohort was composed of two groups of VTE patients depending on the medical therapy that the patient received: LMWH/VKA vs. DOACs, including apixaban, rivaroxaban and dabigatran.

\subsection{Data Collection, Surveillance and Follow-Up}

Data were collected from the computerized system in RMC. Demographic variables, vital signs on admission, relevant laboratory values including $\mathrm{D}$ dimer, imaging study, final diagnosis of DVE and/or PE, a history of VTE, treatment in the ED and following the 
discharge with LMWH and VKA or DOACs, duration of hospitalization, co-morbidities according to the Charlson comorbidity index [18] and previous anti-aggregation and anticoagulation medications were extracted from the patients' computerized medical records.

Patients were followed-up for one year following the hospital admission, for the occurrence of outcomes. Data regarding the type of anticoagulant used for treatment were retrieved from the patients' files and the hospitalization discharge letter. We collected data regarding medications after discharge dispensed by the pharmacy.

\subsection{Outcome Assessments}

The primary outcome was a composite outcome of all-cause mortality, major bleeding events, recurrent VTEs and hospitalizations throughout the FU period of one year. Date of death was retrieved through the hospital administration system, which is updated with Israel's Ministry of Interior data. Secondary outcomes included each of the following: recurrent VTEs, major bleeding events and all-cause mortality in one-year FU, as well as a composite of recurrent VTEs, major bleeding events and all-cause mortality. Major bleeding was defined according to the ISTH definitions as overt bleeding with a decrease in the hemoglobin level of a 2 or more $\mathrm{g} / \mathrm{dL}$, a bleeding that required blood transfusion of more than two units of blood, occurred into a critical site or contributed to death [19].

\subsection{Statistical Analysis}

The statistical analysis was generated using SAS Software, Version 9.4 (SAS Institute, Cary, NC, USA). Continuous variables were presented by mean \pm standard deviation (std). T-Test was used to compare the value of continuous variables between study groups and Fisher's exact test (for two groups) or Chi-square (for more than two groups) were used to compare the value of categorical variables between study groups. Overall survival was assessed by the Kaplan-Meier model, with the log-rank test. The Cox Proportional Hazards model was used to calculate hazard ratios (HR). A multivariable analysis was constructed according to univariable analysis by entering variables that were statistically significant in the univariable analysis, as well as age and gender. Propensity score matching was used to create a matched cohort for the primary outcome. The factors for the propensity analysis were chosen based on comorbidities, as malignancy, on parameters of clinical importance and parameters that may influence the risk for VTE. The model was used to match between the group receiving VKA/LMWH and those that received DOACs using a logistic regression model. The analysis was performed using a caliper equal to 0.2 and based on a 2:1 ratio.

For the secondary endpoints of recurrent VTEs and major bleeding, the Fine and Gray methodology was used to adjust the HR, for the competing risk of death. Medication was included in the Cox model as a time dependent covariate. Two-sided $p$ values less than 0.05 were considered statistically significant.

\section{Results}

\subsection{Study Population}

Overall, 603 patients were identified and included in the final analysis. A total of 476 patients were treated with LMWH/VKA and 127 patients were treated with DOACs. For 42 patients the medication was switched: 39 patients were switched from VKA/LMWH to DOACs and three from DOACs to VKA/LMWH. Baseline characteristics of patients included in the final analysis are presented in Table 1. 
Table 1. Baseline characteristics of patients included in the final analysis.

\begin{tabular}{|c|c|c|c|}
\hline & $\begin{array}{l}\text { VKA Therapy or } \\
\text { Enoxaparin } \\
(n=476)\end{array}$ & $\begin{array}{l}\text { DOACs } \\
(n=127)\end{array}$ & $p$-Value \\
\hline Age (years), (Mean \pm Std) & $79.9 \pm 8.5$ & $78.6 \pm 8.1$ & 0.11 \\
\hline Gender $(n)$ & 476 & 127 & 0.04 \\
\hline Male gender $(n, \%)$ & $213(44.8)$ & $44(34.7)$ & \\
\hline BMI (Mean \pm Std) & $27.1 \pm 6.4(n=287)$ & $29.1 \pm 11.0(n=98)$ & 0.08 \\
\hline \multicolumn{4}{|l|}{ Co-morbidities } \\
\hline Myocardial infarction $(n, \%)$ & $86(18.1)$ & $25(19.7)$ & 0.70 \\
\hline Congestive heart failure $(n, \%)$ & $50(10.6)$ & $14(11.0)$ & 0.87 \\
\hline Peripheral vascular disease $(n, \%)$ & $7(1.5)$ & $1(0.8)$ & 1.00 \\
\hline Cerebrovascular disease $(n, \%)$ & $88(18.5)$ & $27(21.3)$ & 0.53 \\
\hline Dementia $(n, \%)$ & $38(8.0)$ & $8(6.3)$ & 0.71 \\
\hline Chronic pulmonary disease $(n, \%)$ & $62(13.0)$ & $19(15.0)$ & 0.56 \\
\hline Connective tissue disease $(n, \%)$ & $20(4.2)$ & $4(3.2)$ & 0.80 \\
\hline Peptic ulcer disease $(n, \%)$ & $8(1.7)$ & $3(2.4)$ & 0.71 \\
\hline Liver disease $(n, \%)$ & $8(1.7)$ & $3(2.4)$ & 0.71 \\
\hline Diabetic mellitus $(n, \%)$ & $117(24.6)$ & $32(25.2)$ & 0.91 \\
\hline Renal disease $(n, \%)$ & $22(4.6)$ & $3(2.4)$ & 0.32 \\
\hline Malignancy $(n, \%)$ & $96(20.1)$ & $12(9.5)$ & 0.004 \\
\hline $\begin{array}{l}\text { Acquired Immune Deficiency } \\
\text { Syndrome }(n, \%)\end{array}$ & $0(0)$ & $0(0)$ & \\
\hline \multicolumn{4}{|l|}{$\begin{array}{l}\text { Chronic Medications Prior to the } \\
\text { Actual Vte Event }\end{array}$} \\
\hline DOACs & & & $<0.001$ \\
\hline Rivaroxaban $(n, \%)$ & $3(0.6)$ & $10(7.9)$ & \\
\hline Apixaban $(n, \%)$ & $3(0.6)$ & $11(8.7)$ & \\
\hline Dabigatran $(n, \%)$ & $4(0.8)$ & $1(0.8)$ & \\
\hline \multicolumn{4}{|l|}{ Antiplatelets } \\
\hline Aspirin $(n, \%)$ & $181(38.0)$ & 35 (27.6) & 0.03 \\
\hline Clopidogrel $(n, \%)$ & $37(7.8)$ & $18(14.2)$ & 0.04 \\
\hline Prasugrel $(n, \%)$ & $1(0.2)$ & $0(0)$ & 1.00 \\
\hline Ticagrelor $(n, \%)$ & $1(0.2)$ & $0(0)$ & 1.00 \\
\hline Enoxaparin $(n, \%)$ & $56(11.8)$ & $8(6.2)$ & 0.05 \\
\hline $\operatorname{VKA}(n, \%)$ & $63(13.2)$ & $9(7.1)$ & 0.06 \\
\hline \multicolumn{4}{|l|}{ Vital Signs on Admission } \\
\hline Systolic BP (Mean \pm Std) & $134.4 \pm 22.7$ & $137.2 \pm 25.3$ & 0.23 \\
\hline Diastolic BP (Mean \pm Std) & $72.5 \pm 14.6$ & $73.6 \pm 15.2$ & 0.43 \\
\hline Pulse (Mean \pm Std) & $85.2 \pm 17.7$ & $86.5 \pm 19.1$ & 0.47 \\
\hline Fever $($ Mean \pm Std $)$ & $36.9 \pm 0.6$ & $36.9 \pm 0.6$ & 0.73 \\
\hline Saturation (Mean \pm Std) & $94.8 \pm 4.1(n=434)$ & $94.6 \pm 5.3(n=118)$ & 0.71 \\
\hline
\end{tabular}


Table 1. Cont.

\begin{tabular}{|c|c|c|c|}
\hline & $\begin{array}{l}\text { VKA Therapy or } \\
\text { Enoxaparin } \\
(n=476)\end{array}$ & $\begin{array}{l}\text { DOACs } \\
(n=127)\end{array}$ & $p$-Value \\
\hline \multicolumn{4}{|l|}{ Relevant Laboratory Parameters } \\
\hline Platelets (Mean \pm Std) & $\begin{array}{c}245.9 \pm 114.9(n= \\
462)\end{array}$ & $\begin{array}{c}249.9 \pm 98.7(n= \\
125)\end{array}$ & 0.70 \\
\hline Leucocytes (Mean \pm Std) & $12.2 \pm 42.7(n=462)$ & $11.3 \pm 14.2(n=125)$ & 0.70 \\
\hline Hemoglobin (Mean \pm Std) & $11.7 \pm 1.9(n=463)$ & $12.4 \pm 1.7(n=125)$ & $<0.001$ \\
\hline Creatinine (Mean \pm Std) & $1.3 \pm 1.4(n=461)$ & $1.1 \pm 0.8(n=125)$ & 0.20 \\
\hline $\mathrm{pH}($ Mean \pm Std $)$ & $7.4 \pm 0.1(n=203)$ & $7.4 \pm 0.1(n=55)$ & 0.77 \\
\hline D dimer $($ Mean \pm Std $)$ & $\begin{aligned} 9807.6 & \pm 12325.4(n \\
& =52)\end{aligned}$ & $\begin{array}{c}11,026.7 \pm 10,300.7 \\
(n=11)\end{array}$ & 0.76 \\
\hline $\begin{array}{l}\text { Duration of hospitalization (days), } \\
\text { (Median, (Min.Max)) }\end{array}$ & $5(1.50)$ & $4(2.28)$ & 0.01 \\
\hline Prior VTE $(n, \%)$ & $75(15.8)$ & $17(13.4)$ & 0.58 \\
\hline Diagnosis DVT/PE $(n)$ & 476 & 127 & 0.31 \\
\hline $\operatorname{DVT}(n, \%)$ & $111(23.3)$ & $30(23.6)$ & \\
\hline $\operatorname{PE}(n, \%)$ & $106(22.3)$ & $36(28.4)$ & \\
\hline $\mathrm{DVT}+\mathrm{PE}(n, \%)$ & $259(54.4)$ & $61(48.0)$ & \\
\hline
\end{tabular}

VKA = Vitamin K antagonist, BMI = body mass index, $\mathrm{BP}=$ blood pressure, $\mathrm{VTE}=$ venous thromboembolism, DVT $=$ deep vein thrombosis, $\mathrm{PE}=$ pulmonary embolism, $\mathrm{DOACs}=$ direct oral anticoagulants. ${ }^{*}$ Prior anticoagulation treatment was used as therapy for prior VTE or in other indication such as atrial fibrillation.

The mean age was $79.9 \pm 8.5$ years in the VKA/LMWH group and $78.6 \pm 8.1$ years in the DOACs group, $p=0.11$. The duration of hospitalization was longer in the LMWH/VKA by 1.4 days compared to the DOACs group $(7.3 \pm 7.2$ vs. $5.9 \pm 4.9$, respectively, $p=0.01$ ). The co-morbidities according to the Charlson comorbidity index were similarly distributed in the two study groups, except for known malignancy that was more prevalent in the VKA/LMWH group with $20.1 \%$ in compared to $9.5 \%$ in the DOACs group. Previous VTEs events were also similarly distributed in the two study groups.

\subsection{Clinical Outcomes during a Follow-Up Period of One Year}

The number and percentage of events in each outcome are represented in Table 2.

Table 2. Outcomes.

\begin{tabular}{ccc}
\hline & VKA/LMWA $(n=476)$ & $\begin{array}{c}\text { DOACs }(n=127) \\
\text { Rivaroxaban }(n=40) \\
\text { Apixaban }(n=82) \\
\text { Dabigatran }(n=5)\end{array}$ \\
\hline Composite outcome $(n=427)$ & $355(74.6 \%)$ & $72(56.7 \%)$ \\
\hline Major bleeding events $(n=35)$ & $32(6 \%)$ & $3(2 \%)$ \\
\hline Recurrent VTEs $(n=50)$ & $47(10 \%)$ & $3(2 \%)$ \\
\hline All-cause mortality $(n=316)$ & $300(63 \%)$ & $16(13 \%)$ \\
\hline
\end{tabular}

The primary endpoint of a composite outcome of all-cause mortality, major bleeding, recurrent VTE and hospitalizations throughout the FU period occurred in 355/476 patients $(74.6 \%)$ in the VKA/LMWH group and in $72 / 127$ (56.7\%) patients in the DOACs group, hazard ratio (HR) of $0.59,95 \%$ confidence interval (CI) 0.46 to $0.76, p<0.0001$, in favor of the DOACs group. HR for recurrent VTEs and major bleedings events was 0.58 ( $95 \%$ CI 0.26 to 1.28 ) and 1.15 (95\% CI 0.50 to 2.65), respectively, for the DOACs group, 
however without significance ( $p=0.18$ and $p=0.75$, respectively). There was a significant reduction in mortality in the DOACs group-HR $0.30,95 \%$ CI 0.20 to $0.44, p<0.0001$. Details regarding causes of death are provided in the Supplementary Table S1. Overall, 54 patients died from malignancy, which comprises $17.1 \%$ of causes of death. In the VKA/LMWH and DOACs groups 49 and five patients (16\% and $31 \%$ of the mortality events in those groups, respectively) died from cancer. Another common cause of death was sepsis. Of note, there was no information regarding the cause of death in almost $50 \%$ of cases of death. HR for the composite outcome of recurrent VTEs, major bleeding events and all-cause mortality was 0.38 in favor of the DOACs group, 95\% CI (0.27-0.55), $p<0.0001$.

In a multivariable analysis for the primary outcome, treatment with DOACs, as well as age, elevated creatinine levels and malignancy were all associated significantly with the composite outcome of all-cause mortality, major bleeding, recurrent VTE and hospitalizations throughout the FU period of one year, HR of 0.64 (CI of 0.49-0.83) for the treatment with DOACs (Table 3).

Table 3. Multivariable analysis for the composite outcome of all-cause mortality, major bleeding, recurrent VTE and hospitalizations.

\begin{tabular}{ccc}
\hline & HR $\mathbf{( 9 5 \% C I )}$ & $p$ Value \\
\hline Treatment group (DOACs vs. VKA/LMWH) & $0.64(0.49-0.83)$ & 0.001 \\
\hline Male & $1.05(0.86-1.28)$ & 0.64 \\
\hline Age & $1.02(1.01-1.04)$ & 0.0001 \\
\hline Baseline Creatinine & $1.10(1.05-1.15)$ & 0.0002 \\
\hline Malignancy & $2.26(1.78-2.87)$ & $<0.0001$ \\
\hline
\end{tabular}

$\overline{\mathrm{HR}}=$ Hazard ratio; $\mathrm{CI}=$ confidence interval. For continuous variables HR given per 1 unit increment: year (for age), $\mathrm{mg} / \mathrm{dL}$ (for creatinine).

In addition to the analysis above, we also conducted the same analysis on a matched cohort according to gender, age, prior MI, CHF, diabetic mellitus, renal disease, malignancy and prior VTE, in order to ensure that the differences between the groups had minimal influence on our results. In the matched groups there were 214 patients in the VKA/LMWH group and 107 patients in the DOACs group. The analysis on the propensity matched cohort produced the same results as the original analysis, as well for the multivariable analysis, with HR of 0.63 for the DOACs group in the composite outcome, $95 \%$ CI 0.47 to $0.86, p=0.0032$.

\section{Discussion}

In this retrospective, single-center study of 603 elderly patients with VTE, we assessed the efficacy and safety of DOACs, compared with the standard treatment of LMWH followed by VKA. The main finding is a lower rate of the composite outcome of all-cause mortality, major bleeding, recurrent VTE and hospitalizations in patients treated with DOACs compared to LMWH/VKA, with an HR of 0.59 (95\% CI 0.46 to 0.76). These results were also statistically significant in a matched cohort produced by a propensity score analysis. This finding is consistent with the findings of previous studies in younger populations $[1,4,5]$. Regarding our secondary outcome, the HR for recurrent VTEs and major bleedings events was not significant, however there was a significant reduction in mortality in the DOACs group with HR of $0.30,95 \%$ CI 0.20 to $0.44, p<0.0001$. Importantly, this is the first time that a reduction in mortality is demonstrated in the group that was treated with DOACs, which emphasizes the fact that in older age there is a considerable advantage in treatment with DOACs.

Notably, in our analysis there were relatively many mortality events in both groups compared to previous large randomized controlled trials, including the AMPLIFY, RE-MEDY, EINSTEIN and Hokusai-VTE trials [1,4-6], probably due to the older age of this cohort. However, the mean age was similar in both of our groups and mortality rate was significantly lower in the DOACs group. 
The co-morbidities according to the Charlson comorbidity index were similarly distributed between the two study groups, except for malignancies that were more prevalent in the VKA/LMWH group, a finding that is not surprising because LMWH was considered the treatment of choice for VTE in patients with known active malignancy at that time (according to the American College of Chest Physicians (ACCP, CHEST) 2016 guidelines LMWH over VKA therapy was grade 2B, DOACs was grade 2C) [9]. The safety and efficacy of DOACs in cancer-associated thrombosis was thoroughly studied only later, in several trials that demonstrated noninferiority of DOACs: the HOKUSAI trial that evaluated edoxaban [20], the SELECT D published in 2018, that evaluated rivaroxaban [21] and the CARAVAGGIO trial (March 2020) that evaluated apixaban [21]. Current guidelines now recommend specific DOACs (edoxaban or rivaroxaban) to be considered as an alternative to LMWH, with the exception of patients with gastrointestinal cancer [10]. These guidelines do not include the recommendation to consider the use of apixaban because the publication of the CARAVAGGIO study [22] was subsequent to the publication of the current guidelines.

In a multivariable analysis, treatment with DOACs (compared with LMWH/VKA) as well as age, elevated creatinine levels and malignancy were all associated significantly with the composite outcome of all-cause mortality, major bleeding, recurrent VTE and hospitalizations throughout the FU period of one year.

It is not surprising that creatinine levels were associated with mortality as it has previously been shown that chronic kidney disease is a strong prognostic factor for mortality and cardiovascular disease including stroke, coronary artery disease, heart failure and peripheral arterial disease [23]. Furthermore, it has also been shown that patients with nephrotic syndrome have an increased risk of VTE [24] as well as patients receiving maintenance dialysis and kidney transplant recipients $[25,26]$.

Our findings suggest that the use of DOACs may be safe and non-inferior in efficacy to the standard therapy with LMWH/VKA in the elderly. These findings support those of the subgroup analyses of previous RCTs $[1,4,5]$ as well the results of a previously published systematic review and meta-analysis which showed the same or greater efficacy and safety to DOACs over vitamin K antagonists in elderly patients [16,17,27]. In addition, a recent real-life data analysis of the RIETE registry, in which DOACs were compared to LMWH/VKA in fragile patients (defined as age $>75$ or $\mathrm{Crcl}<50 \mathrm{~mL} / \mathrm{min}$ ) showed that patients receiving DOACs for long-term therapy had a significantly lower risk for the composite endpoint of recurrent VTE or major bleeding [28]. In another recent analysis of frail patients with VTE rivaroxaban compared to VKA, reduced the composite of recurrent venous thromboembolism or major bleeding [29]. Additionally, a recently pooled analysis of the RE-COVER and RE-COVER II trials found that dabigatran showed better efficacy than warfarin in the elderly [27], in a shorter follow-up period of six months compared to one year in our trial. Several studies conducted in the elderly population with atrial fibrillation have shown similar results: one trial showed lower mortality rates in DOACs patients and similar bleeding events, and in another trial, low dose edoxaban was superior to placebo in preventing stroke and was not associated with higher incidence of major bleeding than placebo. There was no consensus regarding the risk of stroke in these trials [30,31]. In a recent study evaluating very elderly patients (above 85 years) with AF, there were significantly increasing prescription rates of DOACs following the introduction of DOACs [32].

The current study has several limitations. First, the duration of hospitalization was longer by 1.4 days in the VKA/LMWH compared to the DOACs group, a finding that might imply that the difference between the study groups is possibly that patients in the VKA/LMWH group were more severely ill than patients in the DOACs group. Another option is that patients receiving VKA/LMWH were hospitalized for a longer duration for the purpose of reaching therapeutic INR in case of discharging with VKA or to be instructed in injecting in case of discharging with LMWH. However, as mentioned above, in additional analysis of matched cohort, similar results to the original analysis were obtained. 
The second limitation stems from the retrospective nature of the study and the potential selection bias associated with it. Information regarding use of the drug by the patient was based on computerized systems and it is difficult to confirm whether the drug was indeed taken with good adherence.

A third limitation is that the DOACs group included a small number of patients; 127 patients, which comprised only $21 \%$ of the study cohort, compared to the EINSTEIN, RE-COVER and AMPLIFY trials, in which 1731, 1273 and 2691 patients (50\% of the study cohort) received rivaroxaban, dabigatran and apixaban, respectively. In our study the small number of patients in the DOAC group may be attributed to the fact that the health regulations in Israel limited use of DOACS in the elderly and for the indication of VTE during part of the study period (treatment with DOACs was included in the Healthcare Basket of Israel for the indication of atrial fibrillation from 2014 and for the indication of VTE from 2018).

A fourth limitation is that we cannot extrapolate the results this study to all types of DOACs because there were no patients treated with edoxaban, since edoxaban was not available for use in Israel.

Another limitation is that there was no information regarding the cause of death in almost $50 \%$ of cases.

An additional limitation is that INR levels were not recorded, thus, data regarding time in therapeutic range (TTR) in the VKA group were lacking. The dosages of medications were also not recorded. However, our intent was to examine a real-life situation. Moreover, an Israeli study published in 2015 showed that in patients treated with warfarin for AF, TTR was only $42 \%$ of the time [33].

A final limitation is that the study groups were not balanced in comorbidities, and malignancy was more prevalent in the VKA/LMWH group as discussed above. This finding can possibly partly explain the higher rate of mortality in this group. However, a higher percentage of the patients who died from malignancy or malignancy-related complications were treated with DOACs and in a multivariable analysis of the full cohort both malignancy and treatment with VKA/LMWH were independently associated with mortality. As well, in a propensity-matched cohort analysis (in which cancer was one of its parameters), the results were similar.

Our findings have clinical implications. They suggest that in a population of elderly patients, DOACs are equally effective and safe compared to LMWH/VKAs. The disadvantages of daily subcutaneous injections with LMWH and frequent INR monitoring with VKAs are well-known. The variability of INR during warfarin treatment places the patient at a higher risk for bleeding episodes and reduces the effectiveness of the drug. The advantages of direct oral anticoagulants (DOACs) are lower rates of drug interactions, no need of coagulation monitoring and a shorter half-life compared with VKAs. DOACs also have disadvantages such as the dependence on renal elimination, mainly with dabigatran, and the shorter half-life which may become more significant when a tablet is inadvertently omitted.

\section{Conclusions}

In the elderly population, treatment of VTE with DOACs was associated with a lower rate of the composite outcome of all-cause mortality, major bleeding, recurrent VTE and hospitalizations in a follow up of one year. This finding supports the results of previous RCTs. DOACs are safe and effective for elderly patients with VTE, but future RCTs specifically designed for patients $>65$ years old are recommended.

Supplementary Materials: The following are available online at https:/ / www.mdpi.com/article/10 $.3390 /$ jcm10235673/s1, Table S1: Causes of death. 
Author Contributions: Study conception and design: A.G.-G. and I.A.-D. Acquisition of data: I.A.-D., Y.V. and M.R.I. Analysis and interpretation of data: A.G.-G., I.A.-D., L.L., A.G., G.S. and T.S. Drafting of the work: A.G.-G. and I.A.-D. Critical revision of the manuscript: All authors. Statistical analysis: T.S. Administrative, technical, or material support: A.G.-G. Study supervision: A.G.-G. All authors have read and agreed to the published version of the manuscript.

Funding: This article was partially funded by a grant on behalf of the "Israel Society of Internal Medicine" and "Bayer".

Institutional Review Board Statement: The study was conducted according to the guidelines of the Declaration of Helsinki, and approved by the Institutional Review Board of Rabin Medical Center (RMC) (confirmation number 0165-18-RMC, date of approval 26 March 2018).

Informed Consent Statement: Our study is retrospective and therefore informed consent was waived by the Institutional Review Board.

Data Availability Statement: The data presented in this study are available on request from the corresponding author. The data are not publicly available due to privacy restriction.

Conflicts of Interest: The authors declare no conflict of interest. The funders had no role in the design of the study; in the collection, analyses or interpretation of data; in the writing of the manuscript, or in the decision to publish the results.

\section{References}

1. Agnelli, G.; Buller, H.R.; Cohen, A.; Curto, M.; Gallus, A.; Johnson, M.; Masiukiewicz, U.; Pak, R.; Thompson, J.; Raskob, G.E.; et al. Oral Apixaban for the Treatment of Acute Venous Thromboembolism. N. Engl. J. Med. 2013, 369, 799-808. [CrossRef] [PubMed]

2. Willerson, J.T.; Cohn, J.N.; Holmes, D.R.; Wellens, H.J.J. Cardiovascular Medicine; Springer: London, UK, 2007. [CrossRef]

3. Kearon, C.; Akl, E.A.; Comerota, A.J.; Prandoni, P.; Bounameaux, H.; Goldhaber, S.Z.; Nelson, M.E.; Wells, P.S.; Gould, M.K.; Dentali, F.; et al. Antithrombotic Therapy for VTE Disease: Antithrombotic Therapy and Prevention of Thrombosis, 9th ed: American College of Chest Physicians Evidence-Based Clinical Practice Guidelines. Chest 2012, 141, e419S-e496S. [CrossRef] [PubMed]

4. Schulman, S.; Kearon, C.; Kakkar, A.K.; Mismetti, P.; Schellong, S.; Eriksson, H.; Baanstra, D.; Schnee, J.; Goldhaber, S.Z. Dabigatran versus Warfarin in the Treatment of Acute Venous Thromboembolism. N. Engl. J. Med. 2009, 361, $2342-2352$. [CrossRef] [PubMed]

5. $\quad$ Einstein Investigators; Berkowitz, S.D.; Brenner, B.; Buller, H.R.; Décousus, H.; Gallus, A.S.; Lensing, A.W.; Misselwitz, F.; Prins, M.H.; E Raskob, G.; et al. Oral Rivaroxaban for Symptomatic Venous Thromboembolism. N. Engl. J. Med. 2010, 363, 2499-2510. [CrossRef]

6. Hokusai-VTE Investigators. Edoxaban versus Warfarin for the Treatment of Symptomatic Venous Thromboembolism. N. Engl. J. Med. 2013, 369, 1406-1415. [CrossRef]

7. Lanitis, T.; Leipold, R.; Hamilton, M.; Rublee, D.; Quon, P.; Browne, C.; Cohen, A.T. Cost-effectiveness of apixaban versus low molecular weight heparin/vitamin $\mathrm{k}$ antagonist for the treatment of venous thromboembolism and the prevention of recurrences. BMC Health Serv. Res. 2017, 17, 74. [CrossRef] [PubMed]

8. Stevanovic, J.; De Jong, L.A.; Kappelhoff, B.S.; Dvortsin, E.P.; Voorhaar, M.; Postma, M.J. Dabigatran for the Treatment and Secondary Prevention of Venous Thromboembolism; A Cost-Effectiveness Analysis for the Netherlands. PLoS ONE 2016, 11, e0163550. [CrossRef] [PubMed]

9. Kearon, C.; Akl, E.A.; Ornelas, J.; Blaivas, A.; Jimenez, D.; Bounameaux, H.; Huisman, M.; King, C.S.; Morris, T.A.; Sood, N.; et al. Antithrombotic Therapy for VTE Disease: CHEST Guideline and Expert Panel Report. Chest 2016, 149, 315-352. [CrossRef] [PubMed]

10. Konstantinides, S.V.; Meyer, G.; Becattini, C.; Bueno, H.; Geersing, G.J.; Harjola, V.P.; Huisman, M.V.; Humbert, M.; Jennings, C.S.; Jiménez, D.; et al. 2019 ESC Guidelines for the diagnosis and management of acute pulmonary embolism developed in collaboration with the European Respiratory Society (ERS). Eur. Heart J. 2020, 41, 543-603. [CrossRef]

11. Ortel, T.L.; Neumann, I.; Ageno, W.; Beyth, R.; Clark, N.P.; Cuker, A.; Hutten, B.A.; Jaff, M.R.; Manja, V.; Schulman, S.; et al. American Society of Hematology 2020 guidelines for management of venous thromboembolism: Treatment of deep vein thrombosis and pulmonary embolism. Blood Adv. 2020, 4, 4693-4738. [CrossRef]

12. Stein, P.D.; Hull, R.D.; Kayali, F.; Ghali, W.A.; Alshab, A.K.; Olson, R.E. Venous Thromboembolism According to Age. Arch. Intern. Med. 2004, 164, 2260-2265. [CrossRef]

13. Heit, J.A.; Mohr, D.N.; Silverstein, M.D.; Petterson, T.M.; O’Fallon, W.M.; Melton, L.J. Predictors of Recurrence After Deep Vein Thrombosis and Pulmonary Embolism. Arch. Intern. Med. 2000, 160, 761-768. [CrossRef] [PubMed]

14. Bauersachs, R.M. Use of anticoagulants in elderly patients. Thromb. Res. 2012, 129, 107-115. [CrossRef] [PubMed] 
15. Nieto, J.A.; Solano, R.; Ruiz-Ribo, M.D.; Ruiz-Gimenez, N.; Prandoni, P.; Kearon, C.; Monreal, M.; Riete Investigators. Fatal bleeding in patients receiving anticoagulant therapy for venous thromboembolism: Findings from the RIETE registry: Fatal bleeding during anticoagulant therapy. J. Thromb. Haemost. 2010, 8, 1216-1222. [CrossRef]

16. Sadlon, A.H.; A Tsakiris, D. Direct oral anticoagulants in the elderly: Systematic review and meta-analysis of evidence, current and future directions. Swiss Med. Wkly. 2016, 146, w14356. [CrossRef] [PubMed]

17. Geldhof, V.; Vandenbriele, C.; Verhamme, P.; Vanassche, T. Venous thromboembolism in the elderly: Efficacy and safety of non-VKA oral anticoagulants. Thromb. J. 2014, 12, 21. [CrossRef]

18. Quan, H.; Li, B.; Couris, C.M.; Fushimi, K.; Graham, P.; Hider, P.; Januel, J.-M.; Sundararajan, V. Updating and Validating the Charlson Comorbidity Index and Score for Risk Adjustment in Hospital Discharge Abstracts Using Data From 6 Countries. Am. J. Epidemiol. 2011, 173, 676-682. [CrossRef]

19. Schulman, S.; Kearon, C.; The Subcommittee on Control of Anticoagulation of the Scientific and Standardization Committee of the International Society on Thrombosis and Haemostasis. Definition of major bleeding in clinical investigations of antihemostatic medicinal products in non-surgical patients. J. Thromb. Haemost. 2005, 3, 692-694. [CrossRef]

20. Raskob, G.E.; Van Es, N.; Verhamme, P.; Carrier, M.; Di Nisio, M.; Garcia, D.; Grosso, M.A.; Kakkar, A.K.; Kovacs, M.J.; Mercuri, M.F.; et al. Edoxaban for the Treatment of Cancer-Associated Venous Thromboembolism. N. Engl. J. Med. 2018, 378, 615-624. [CrossRef] [PubMed]

21. Young, A.M.; Marshall, A.; Thirlwall, J.; Chapman, O.; Lokare, A.; Hill, C.; Hale, D.; Dunn, J.A.; Lyman, G.H.; Hutchinson, C.; et al. Comparison of an Oral Factor Xa Inhibitor With Low Molecular Weight Heparin in Patients With Cancer With Venous Thromboembolism: Results of a Randomized Trial (SELECT-D). J. Clin. Oncol. 2018, 36, 2017-2023. [CrossRef]

22. Agnelli, G.; Becattini, C.; Meyer, G.; Muñoz, A.; Huisman, M.V.; Connors, J.M.; Cohen, A.; Bauersachs, R.; Brenner, B.; Torbicki, A.; et al. Apixaban for the Treatment of Venous Thromboembolism Associated with Cancer. N. Engl. J. Med. 2020, 382, $1599-1607$. [CrossRef]

23. Go, A.S.; Chertow, G.M.; Fan, D.; McCulloch, C.E.; Hsu, C.-Y. Chronic Kidney Disease and the Risks of Death, Cardiovascular Events, and Hospitalization. N. Engl. J. Med. 2004, 351, 1296-1305. [CrossRef] [PubMed]

24. Kayali, F.; Najjar, R.; Aswad, F.; Matta, F.; Stein, P.D. Venous Thromboembolism in Patients Hospitalized with Nephrotic Syndrome. Am. J. Med. 2008, 121, 226-230. [CrossRef]

25. Tveit, D.P.; Hypolite, I.O.; Hshieh, P.; Cruess, D.; Agodoa, L.Y.; Welch, P.G.; Abbott, K. Chronic dialysis patients have high risk for pulmonary embolism. Am. J. Kidney Dis. 2002, 39, 1011-1017. [CrossRef] [PubMed]

26. Abbott, K.C.; Cruess, D.F.; Agodoa, L.Y.; Sawyers, E.S.; Tveit, D.P. Early renal insufficiency and late venous thromboembolism after renal transplantation in the united states. Am. J. Kidney Dis. 2004, 43, 120-130. [CrossRef] [PubMed]

27. Goldhaber, S.Z.; Schulman, S.; Eriksson, H.; Feuring, M.; Fraessdorf, M.; Kreuzer, J.; Schüler, E.; Schellong, S.; Kakkar, A. Dabigatran versus Warfarin for Acute Venous Thromboembolism in Elderly or Impaired Renal Function Patients: Pooled Analysis of RE-COVER and RE-COVER II. Thromb. Haemost. 2017, 117, 2045-2052. [CrossRef]

28. López-Núñez, J.J.; Pérez-Andrés, R.; Di Micco, P.; Schellong, S.; Gómez-Cuervo, C.; Sahuquillo, J.C.; Ciammaichella, M.; Morales, M.D.V.; Bosevski, M.; Monreal, M.; et al. Direct Oral Anticoagulants or Standard Anticoagulant Therapy in Fragile Patients with Venous Thromboembolism. TH Open 2019, 3, e67-e76. [CrossRef]

29. Coleman, C.I.; Turpie, A.G.; Bunz, T.J.; Beyer-Westendorf, J. Effectiveness and Safety of Rivaroxaban Versus Warfarin in Frail Patients with Venous Thromboembolism. Am. J. Med. 2018, 131, 933-938.e1. [CrossRef]

30. Poli, D.; Antonucci, E.; Ageno, W.; Bertù, L.; Migliaccio, L.; Martinese, L.; Pilato, G.; Testa, S.; Palareti, G. Oral anticoagulation in very elderly patients with atrial fibrillation: Results from the prospective multicenter START2-REGISTER study. PLoS ONE 2019, 14, e0216831. [CrossRef]

31. Okumura, K.; Akao, M.; Yoshida, T.; Kawata, M.; Okazaki, O.; Akashi, S.; Eshima, K.; Tanizawa, K.; Fukuzawa, M.; Hayashi, T.; et al. Low-Dose Edoxaban in Very Elderly Patients with Atrial Fibrillation. N. Engl. J. Med. 2020, 383, 1735-1745. [CrossRef] [PubMed]

32. Cheng, W.-H.; Chiang, C.-E.; Lin, Y.-J.; Chang, S.-L.; Lo, L.-W.; Hu, Y.-F.; Tuan, T.-C.; Liao, J.-N.; Chung, F.-P.; Chen, T.-J.; et al. Non-Vitamin K Antagonist Oral Anticoagulants in Elderly ( $\geq 85$ years) Patients With Newly Diagnosed Atrial Fibrillation. Mayo Clin. Proc. 2021, 96, 52-65. [CrossRef]

33. Haim, M.; Hoshen, M.; Reges, O.; Rabi, Y.; Balicer, R.; Leibowitz, M. Prospective National Study of the Prevalence, Incidence, Management and Outcome of a Large Contemporary Cohort of Patients With Incident Non-Valvular Atrial Fibrillation. J. Am. Heart Assoc. 2015, 4, e001486. [CrossRef] 